Prepared for the U.S. Department of Energy under Contract DE-AC05-76RL01830

\title{
Guidelines for Estimating Unmetered Industrial Water Use
}

BK Boyd

August 2010

Pacific Northwest

NATIONAL LABORATORY

Proudly Operated by Battelle Since 1965 


\section{DISCLAIMER}

This report was prepared as an account of work sponsored by an agency of the United States Government. Neither the United States Government nor any agency thereof, nor Battelle Memorial Institute, nor any of their employees, makes any warranty, express or implied, or assumes any legal liability or responsibility for the accuracy, completeness, or usefulness of any information, apparatus, product, or process disclosed, or represents that its use would not infringe privately owned rights. Reference herein to any specific commercial product, process, or service by trade name, trademark, manufacturer, or otherwise does not necessarily constitute or imply its endorsement, recommendation, or favoring by the United States Government or any agency thereof, or Battelle Memorial Institute. The views and opinions of authors expressed herein do not necessarily state or reflect those of the United States Government or any agency thereof.

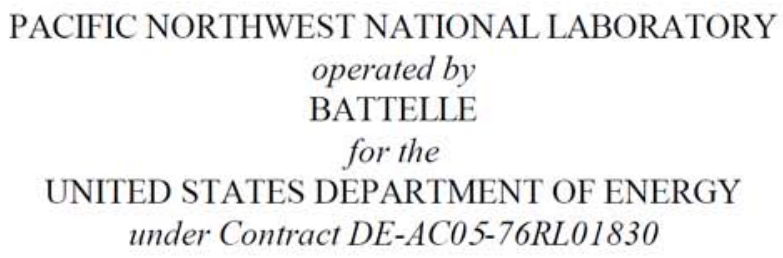

Printed in the United States of America

Available to DOE and DOE contractors from the

Office of Scientific and Technical Information,

P.O. Box 62, Oak Ridge, TN 37831-0062;

ph: (865) 576-8401

fax: (865) $576-5728$

email: reports@adonis.osti.gov

\footnotetext{
Available to the public from the National Technical Information Service, U.S. Department of Commerce, 5285 Port Royal Rd., Springfield, VA 22161 ph: (800) 553-6847 fax: (703) 605-6900

email: orders@ntis.fedworld.gov

online ordering: http://www.ntis.gov/ordering.htm
}

This document was printed on recycled paper. 
PNNL-19730

\section{Guidelines for Estimating Unmetered Industrial Water Use}

BK Boyd

August 2010

Prepared for

U.S. Department of Energy

Federal Energy Management Program under Contract DE-AC05-76RL01830

Pacific Northwest National Laboratory

Richland, Washington 99352 


\section{Summary}

Executive Order 13514 requires Federal agencies to develop a baseline for industrial, landscaping, and agricultural water use in fiscal year 2010. Measuring actual water use through flow meters is the best method to develop this baseline. But there are instances where Federal sites do not meter these applications, so developing a baseline will be problematic. Therefore the intent of this document is to assist Federal agencies in the baseline development by providing a methodology to calculate unmetered sources of industrial water use utilizing engineering estimates.

The document lays-out a systematic approach to estimate industrial water use in evaporative cooling systems, steam boiler systems, and facility wash applications. 


\section{Acknowledgments}

This document was prepared by the Pacific Northwest National Laboratory (PNNL) on behalf of the Federal Energy Management Program. PNNL would like to thank the Federal Water Working Group of the Interagency Energy Management Task Force, which provided initial direction and later review of the supplemental guidance.

Representatives of the working group include the following individuals:

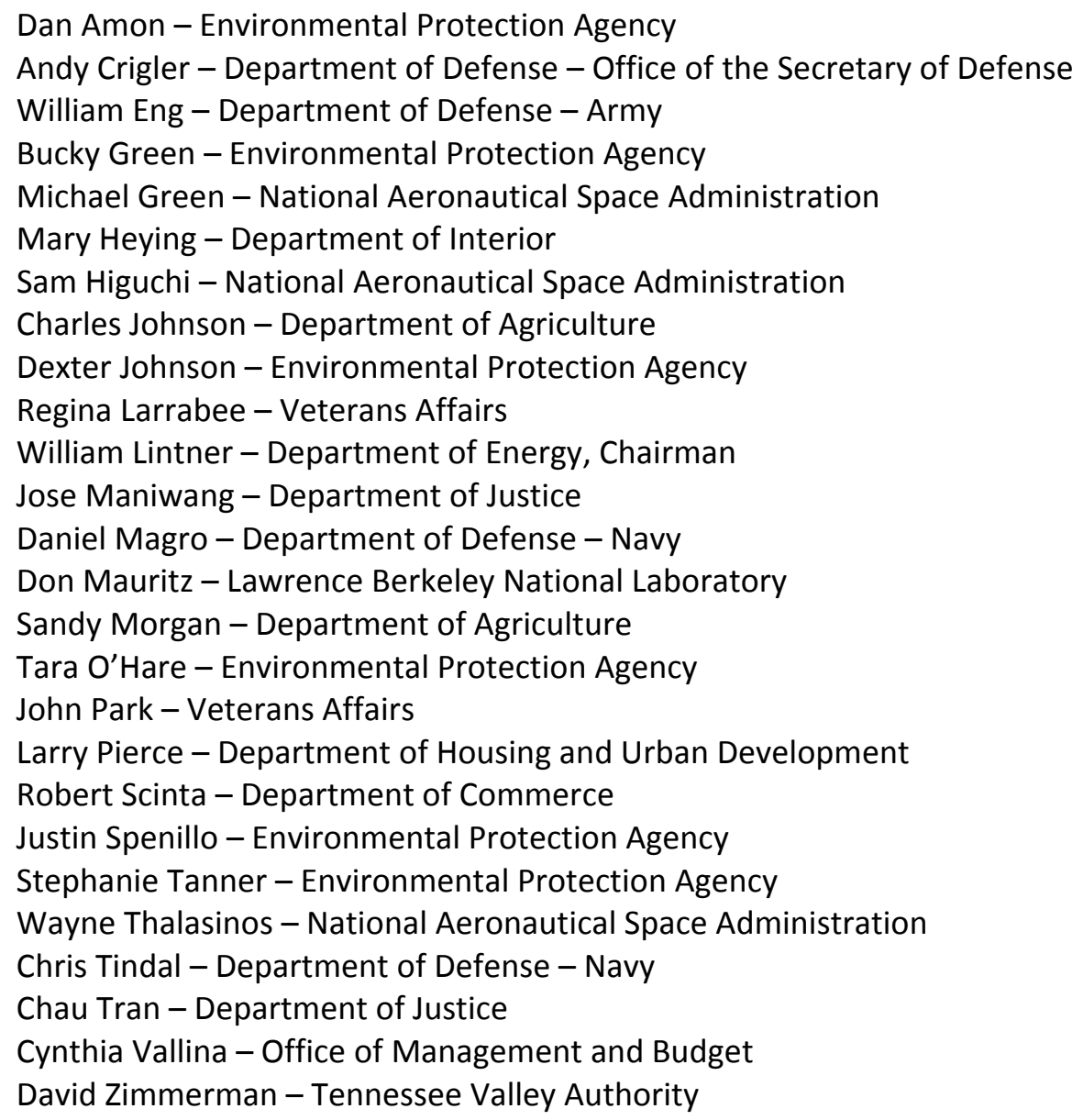

The following people also provided technical and production assistance:

Sue Arey - Pacific Northwest National Laboratory Jim Cabe - Pacific Northwest National Laboratory Elisabeth Giever - Pacific Northwest National Laboratory Bill Sandusky - Pacific Northwest National Laboratory Kate McMordie Stoughton - Pacific Northwest National Laboratory 


\section{Contents}

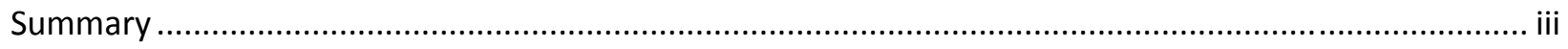

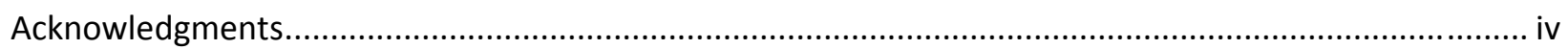

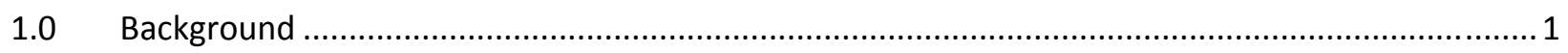

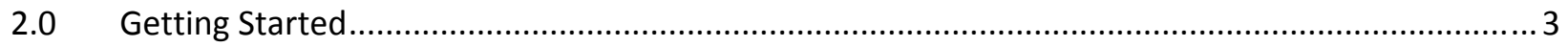

3.0 Estimating Evaporative Cooling System Water Use.............................................................. 5

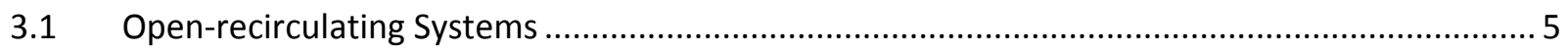

4.0 Estimating Steam Heating System Water Use ....................................................................... 9

4.1 Option 1: Estimating Steam System Water Use Knowing Softener Performance ...................... 11

4.2 Option 2: Determining Heating System Water Use Knowing Your Steam Generation Rate ......12

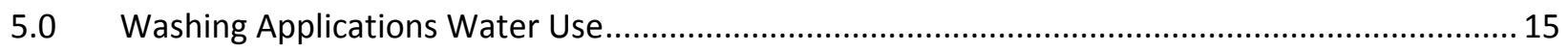

5.1 Wash Applications and Batch Processing/Manufacturing Usages …..................................... 15

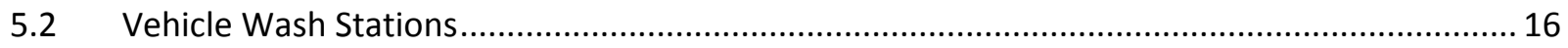

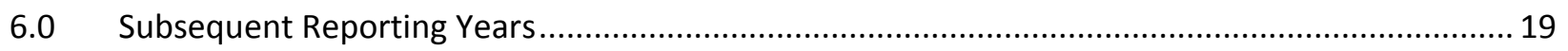

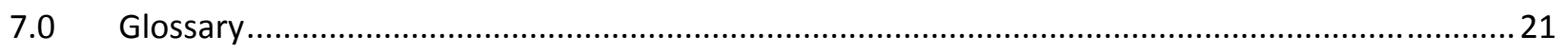

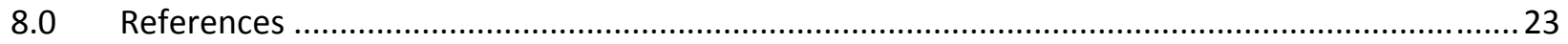

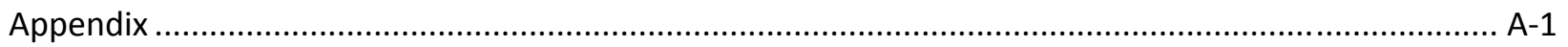

A- 1 Total Dissolved Solids and Conductivity ....................................................................... A-1

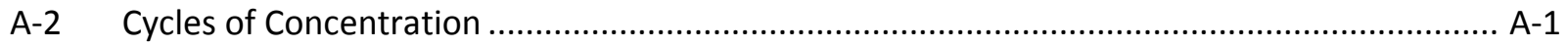

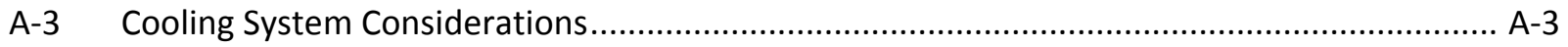

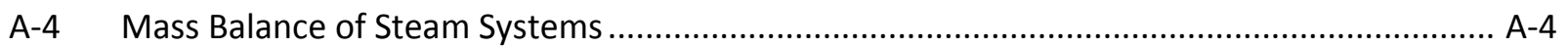

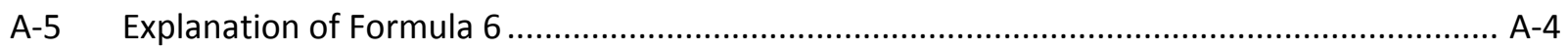

A-6 Steam Heating System Example …................................................................................. A-5

A-7 Vehicle Wash Considerations ............................................................................................... A-7

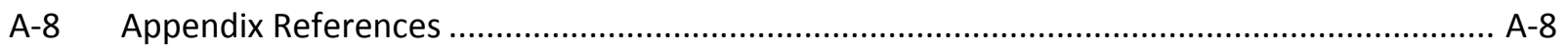




\section{Figures}

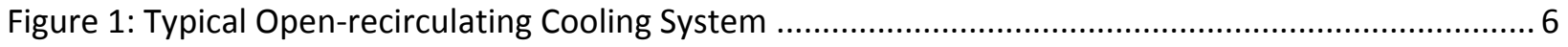

Figure 2: Example Steam Generating Boiler System............................................................................. 10

Figure A 1: Cycles of Concentration and Mass Flow Example of a Steam System.................................... 2

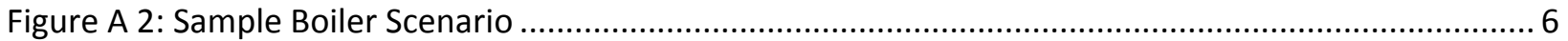

\section{Tables}

Table 1: Million Gallons per Year of Cooling System Usage for Different Sized ...................................... 7

Table 2: Estimating Annual Usage Without Reclaim Systems, ................................................................ 17

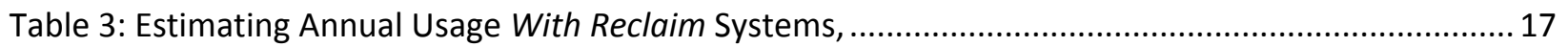

Table 4: Average Fresh Water Usage by Car Wash Type ….................................................................. 7

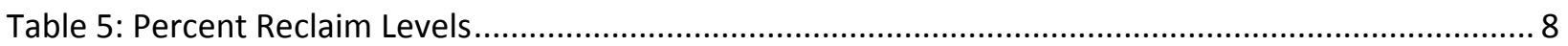




\subsection{Background}

Executive Order 13514, Federal Leadership in Environmental, Energy, and Economic Performance, was signed on October 5, 2009 by President Obama. EO 13514 has water provisions that require Federal agencies to improve water use efficiency and management as follows:

1. Reduce potable water use $2 \%$ annually through fiscal year (FY) 2020 , or $26 \%$ by the end of fiscal year 2020, relative to a fiscal year 2007 baseline.

2. Reduce agency industrial, landscaping, and agricultural non-potable water use $2 \%$ annually, or $20 \%$ by the end of fiscal year 2020, relative to a fiscal year 2010 baseline.

Each Federal site must develop a baseline for these industrial, landscaping, and agricultural uses and report the total FY 2010 consumption to their respective agency. But there are instances where Federal sites do not meter these applications, so developing a baseline will be problematic. The best solution to this problem is to install flow meters. Metering offers the most accurate accounting of water use. If permanent metering is not practical, a temporary flow meter offers the second best solution. There are temporary ultra-sonic flow meters that can be installed to the outside of the pipe that do not require a disruption of the process.

If these metering options are not applicable or practical, then an engineering estimate must be used to estimate annual water use. The intent of this document is to assist Federal agencies in estimating unmetered use of industrial water utilizing engineering estimates ${ }^{1}$.

Industrial water use includes water used for such purposes as fabricating, processing, washing, diluting, cooling, or transporting a product; incorporating water into a product; or for sanitation needs within the facility (USGS 2000). The applications selected for this document are open-recirculating cooling systems, steam generating heating systems, and installation wash facilities. These processes were selected because they represent typical industrial applications at Federal sites.

To help Federal agencies estimate unmetered uses, the following information provides a methodology to estimate requirements for cooling systems, steam heating systems, and wash facilities. The approach incorporates standard calculations, industry norms, general rules of thumb, and industry survey information to provide methodologies for each section.

\footnotetext{
${ }^{1}$ Note, the Federal Energy Management Program has produced a companion document that provides a methodology on how to estimate unmetered landscape irrigation applications.
} 


\subsection{Getting Started}

Using this document, you need to know the following factors to estimate the annual water use for each process covered in this document:

Evaporative cooling system water use, you need to know:

1. Chiller tonnage (nameplate)

2. Cooling tower cycles of concentration

3. Annual days or hours of operation

Steam heating system water use, you need to know either:

1. Estimated amount of water provided by the softener system between regenerations

2. Frequency of softener regeneration

Or:

1. Steam generation rates from your boiler system(s)

2. Boiler blowdown rate or cycles of concentration

3. Condensate return rate

4. Annual days or hours of operation

Wash application(s) water use, you need to know:

1. The number of units annually washed, processed, or manufactured

2. The amount of water needed to wash, process, or manufacture each unit in gallons

3. Whether any recycle/reclaim operation is used, expressed as a percentage

Because these uses cover three distinct, yet separate applications, the information offered is divided into three sections providing methodology to estimate your use for each.

Definitions of key terms and background calculations are discussed in greater detail in the glossary and appendix. 


\subsection{Estimating Evaporative Cooling System Water Use}

For determinations of water use in your cooling system(s), it is important to initially state, the calculations in this document apply only to open-recirculating systems that have evaporative loss ${ }^{2}$. The closed-loop portion of your cooling system(s) should not have significant water losses; therefore, the contribution of the closed-loop towards your annual usage should be negligible.

\subsection{Open-recirculating Systems}

Open-recirculating cooling systems (as shown in figure 1) utilize the evaporation process to provide process or comfort cooling. Warm water returns to the cooling tower after the transfer of process or building heat in a heat exchanger ${ }^{3}$. The warm water is evenly sprayed in the top of a cooling tower structure, where it flows counter-currently to air that is pushed or pulled through the tower fill by the tower fan. The system depends on maximizing the water surface area, allowing it to transfer heat from the working fluid (water) to the air passing through the tower. This encompasses the evaporation process.

By design, cooling towers consume large volumes of water through this process to maintain comfort cooling or process cooling needs, although they use significantly less water than similar capacity oncethrough cooling systems. Additionally, water is lost from any system leaks and tower "drift" (escape of water droplets from the cooling tower structure as a result of system air flow and wind-effect air flow). Because the evaporative loss is water containing little to no dissolved solids, the water remaining in the cooling tower becomes concentrated with dissolved solids, which can lead to scaling and corrosive conditions. To combat these problems, water with high total dissolved solid content must be drained from the system via "blowdown". The associated losses caused by blowdown, evaporation, drift, and system leaks must be accounted for by system make-up requirements. The water used in a cooling system, therefore, is the total amount of make-up water needed by the associated system.

\footnotetext{
${ }^{2}$ Estimating water use of once-through cooling systems is not discussed in detail in this document. This water use can be calculated by multiplying the discharge flow rate (gallons per minute) by the run time per day (minutes) and by the number of days operated per year.

${ }^{3}$ Common heat exchangers include plate-and-frame and tube-in-shell. Chillers are also prevalent in many applications. Regardless, the heat exchanger will be rated for a certain cooling capacity, or refrigeration tonnage.
} 


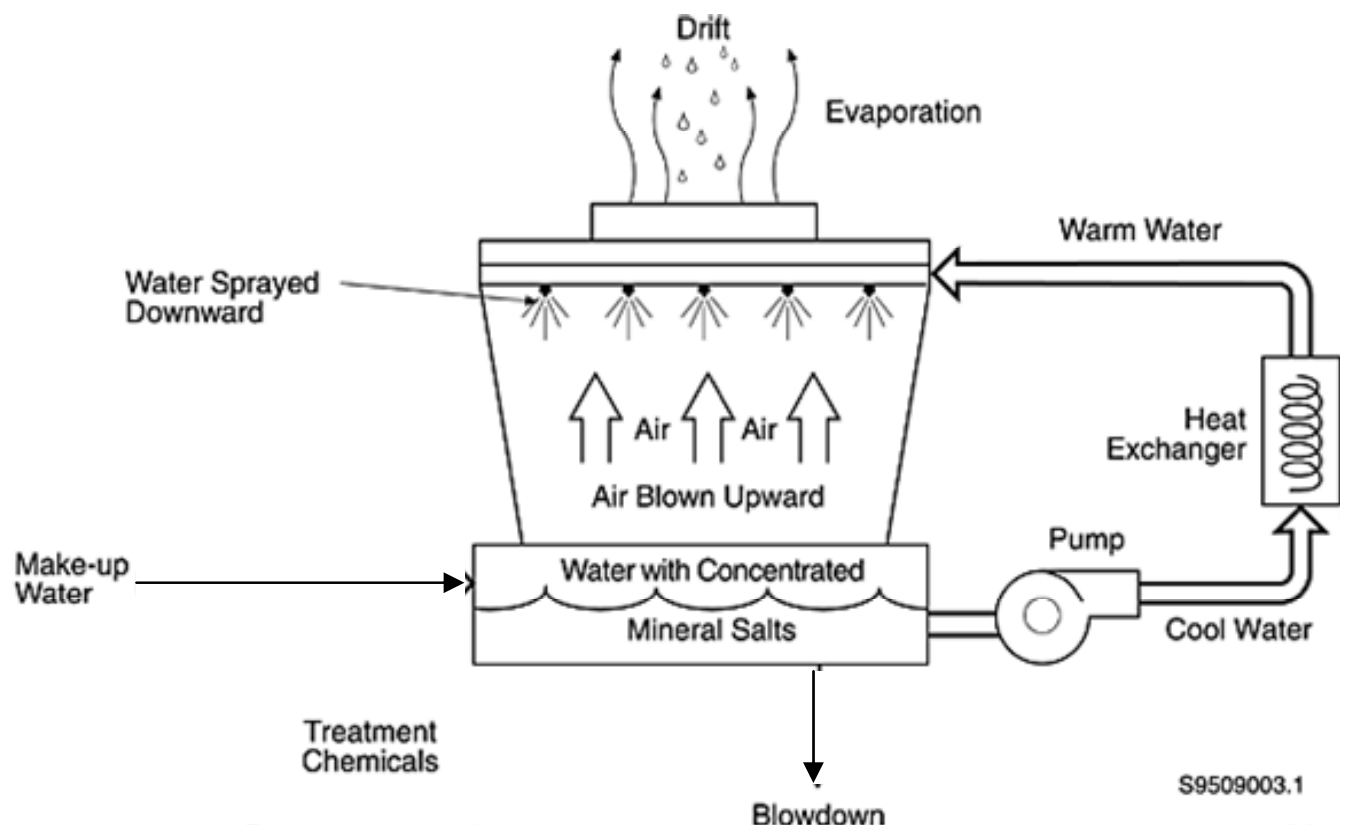

Figure 1: Typical Open-recirculating Cooling System

A key parameter when estimating water use in open-recirculating cooling systems is "cycles of concentration". Cycles of concentration is defined as the number of times that water is concentrated in the cooling tower (Buecker 1997, pg. 161). This is calculated as the ratio of the concentration of dissolved solids in the blowdown water compared to the make-up water. To find more information on cycles of concentration and how you can estimate this for your system, go to section 9.2 of the appendix at the end of this document.

This document allows you to estimate these losses knowing the following items:

1. Chiller tonnage (nameplate)

2. Cooling tower cycles of concentration

3. Annual days or hours of operation

Each individual system should be assessed and estimated independently because each system will have varying chiller tonnage ratings, and likely run at slightly different cycles of concentration. Operating conditions and individual control systems will determine the operating characteristics. Particularly, if your systems have differing blowdown control mechanisms (automated controls may blowdown based on conductivity set-point, timer, or additional system measurements; other systems are blown down manually on a set schedule). 
Knowing your cooling tonnage requirements, and cooling tower cycles of concentration, Table $1^{4}$ provides relative levels of system usage annually:

Table 1: Million Gallons per Year of Cooling System Usage for Different Sized Chillers at Varying Cycles of Concentration ${ }^{5}$

\begin{tabular}{|c|c|c|c|c|c|c|}
\hline \multicolumn{7}{|c|}{ Tower Usage (Million Gallons/Year) } \\
\hline $\begin{array}{c}\text { Chiller } \\
\text { Tonnage } \\
\text { (Nameplate) }\end{array}$ & $\mathbf{3}$ & $\mathbf{4}$ & $\mathbf{5}$ & $\mathbf{6}$ & $\mathbf{7}$ & $\mathbf{8}$ \\
\cline { 2 - 7 } & & & 1.7 & 1.6 & 1.6 & 1.5 \\
\hline $\mathbf{1 0 0}$ & 2.0 & 3.6 & 3.4 & 3.2 & 3.1 & 3.1 \\
\hline $\mathbf{2 0 0}$ & 4.0 & 7.2 & 6.7 & 6.4 & 6.3 & 6.1 \\
\hline $\mathbf{4 0 0}$ & 8.0 & 8.9 & 8.4 & 8.0 & 7.8 & 7.7 \\
\hline $\mathbf{5 0 0}$ & 10.0 & 10.7 & 10.0 & 9.7 & 9.4 & 9.2 \\
\hline $\mathbf{6 0 0}$ & 12.1 & 14.3 & 13.4 & 12.9 & 12.5 & 12.3 \\
\hline $\mathbf{8 0 0}$ & 16.1 & 17.9 & 16.8 & 16.1 & 15.6 & 15.3 \\
\hline $\mathbf{1 0 0 0}$ & 20.1 & 26.8 & 25.1 & 24.1 & 23.5 & 23.0 \\
\hline $\mathbf{1 5 0 0}$ & 30.2 & 35.7 & 33.5 & 32.2 & 31.2 & 30.6 \\
\hline $\mathbf{2 0 0 0}$ & 40.2 & 44.7 & 41.9 & 40.2 & 39.1 & 38.3 \\
\hline $\mathbf{2 5 0 0}$ & 50.3 & 60.3 & 46.3 & 46.0 \\
\hline $\mathbf{3 0 0 0}$ & 60.3 & 53.6 & 50.3 & 48.3 & 46.9 & 53.6 \\
\hline $\mathbf{3 5 0 0}$ & 70.4 & 62.6 & 58.6 & 56.3 & 54.7 & 61.3 \\
\hline $\mathbf{4 0 0 0}$ & 80.4 & 71.5 & 67.0 & 64.3 & 62.6 & 76.6 \\
\hline $\mathbf{5 0 0 0}$ & 100.5 & 89.6 & 83.8 & 80.4 & 78.2 & \\
\hline & & & & & & \\
\hline
\end{tabular}

The usage levels presented in the table above are for year-round operations ( 8760 hours). If your cooling needs are intermittent or seasonal, you will also need to incorporate the number of days or hours the system operates, as shown in the example below:

\footnotetext{
${ }^{4}$ The baseline formulas used to calculate the values in this table are provided in section 9.3 of the appendix.

${ }^{5}$ The table values are rounded up or down accordingly because the table is intended to make an annual estimate. To achieve more precise calculations, you will need to use the calculations in section 9.3 of the appendix.
} 
A Federal facility has three chillers running in parallel rated at 400 tons per chiller (total of 1200 tons of refrigeration), and an associated open-recirculating cooling tower system. The cooling tower is determined to be running at five cycles of concentration, and the system provides comfort cooling for an average of 2000 hours each year.

Here are the steps to determine the water use for this system:

1. Locate the value in Table 1, corresponding to a 400-ton chiller, with a cooling tower running at five cycles of concentration.

2. Because there are three 400 -ton chillers, multiply this value by 3 .

3. Because the system only runs for 2000 hours, the chiller consumption will be prorated by dividing the actual hours by the year-round hours, as shown in the example calculation below.

Applying this information in a calculation, you will get:

Formula 1: Total Annual Use $\left(\frac{\text { gal }}{\text { year }}\right)=3 \times$ Chiller Consumption $\times \frac{\text { Run time }}{8760 \text { hours }}$

$$
\begin{aligned}
\text { Total Annual Use }\left(\frac{\text { gal }}{\text { year }}\right) & =3 \times 6.7 \frac{\text { million gal }}{\text { year }} \times \frac{2000 \text { hours }}{8760 \text { hours }} \\
= & \mathbf{4 . 6} \frac{\text { million gal }}{\mathbf{y e a r}}
\end{aligned}
$$




\subsection{Estimating Steam Heating System Water Use}

For determining water usage in heating systems, the calculations in this document only apply to steam generation systems. Hot-water systems are considered closed-loop, and therefore, should not be considered a component of your annual water usage. Steam generating systems, on the other hand, will have losses caused by blowdown and losses in the associated steam and condensate system that should be estimated and reported.

This section provides you two methods to estimate the total annual water use associated with your steam generating boiler system(s) by knowing either of the following:

1. Softener Performance

Or:

2. Steam Generation Rate

Steam generating boiler systems capitalize on water's ability to hold large amounts of thermal heat energy, and for this heat energy to be transported easily by pressurized steam. Your boiler system was designed to meet the required heating or process load for your facility. Central to the steam heat process is your boiler system, where fuel (coal, natural gas, or fuel oil) is burned to generate a regulated amount of steam at a specific pressure. Figure 2 on the following page illustrates a typical steam boiler system. 


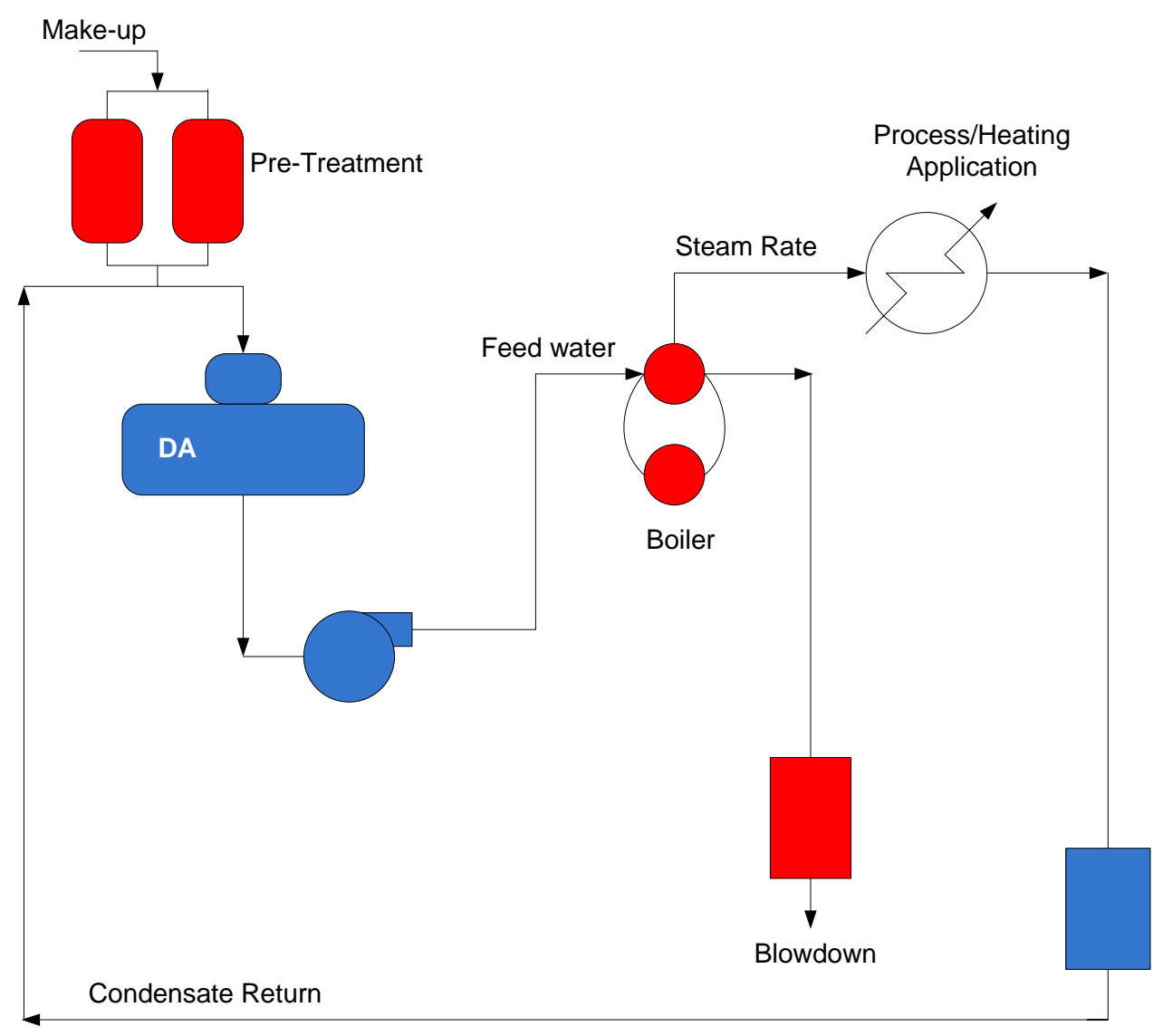

Condensate Return System

Figure 2: Example Steam Generating Boiler System

To achieve the needed steam generation rate, make-up water flows into the system through the pretreatment equipment. This initial layer of equipment may consist of a softener, or series of softeners. In some cases this system may be more complex, consisting of sediment filters, reverse osmosis systems, or demineralization systems ${ }^{6}$. Regardless of the complexity, the purpose of the pre-treatment is initial conditioning of the make-up water to improve water quality according to boiler feed water specifications. From the pre-treatment, make-up water combines with condensate return in a deaerator (noted as DA in the figure) or feed water tank as the source water for the boiler. In the boiler, steam is produced according to facility process or heating needs. The other stream departing the boiler is blowdown. Blowdown is required because steam by nature is very pure, consequently dissolved minerals concentrate in the boiler bulk water. To regulate this concentrating affect, a portion of the boiler bulk water must be discharged from the boiler. This is known as blowdown.

The steam flows from your boiler to the various different heating requirements at your facility. In conjunction with the transfer of energy from the steam to your process or heating application, the

\footnotetext{
${ }^{6}$ Definitions of technical terms are provided in the glossary.
} 
steam undergoes a phase change, condensing back into very hot water. The condensed steam can be pumped back to the boiler feed water system via a condensate return loop.

The losses from the system occur in the process or heating applications, from any steam or condensate leaks, and from blowdown. These losses must be accounted for by system make-up water requirements to keep the system in balance and functioning correctly. The water used in the heating system, therefore, is equal to the amount of make-up water needed to supply your steam generating system. In simple terms, the required make-up water is equal to the losses from the system from blowdown and any losses in the steam and condensate system, represented in the following equation:

Formula 2: Make - up $\left(\frac{\text { gal }}{\text { time }}\right)=$ Blowdown $\left(\frac{\text { gal }}{\text { time }}\right)+$ Steam and Condensate System Losses $\left(\frac{g a l}{\text { time }}\right)$

\subsection{Option 1: Estimating Steam System Water Use Knowing Softener Performance}

The first method to estimate steam system water usage can be used if you can estimate the amount of make-up water coming into the boiler system based on softener performance ${ }^{7}$. Your softener system provides a certain amount of make-up water before it becomes exhausted and needs to be regenerated. If you can determine the approximate amount of water provided by your softener(s) and the regularity the system is regenerated, you have the means to estimate make-up water use for your steam boiler system.

To use this methodology, you need to know:

1. Estimated amount of water provided by the softener system between regenerations

2. Frequency of softener regeneration

To determine both items, refer to the operation manual or, if needed, contact the supplier directly. The system was programmed to regenerate after providing a certain volume of water, and this volume may be recorded in the manual or can be provided by the softener supplier. Additionally, the frequency of softener regeneration may be recorded in the manual in accordance with the amount of salt used by the softeners and the schedule that salt needs to be added. If the softener regeneration frequency isn't in the manual, this can also be provided by the softener supplier. Use these two items in the following equation to estimate annual steam system water use:

$$
\begin{aligned}
& \text { Formula 3: Make }- \text { up }\left(\frac{\text { gal }}{\text { year }}\right) \\
& \qquad=\text { Volume of softened water }\left(\frac{\text { gal }}{\text { regen }}\right) \times \text { Annual softener regenerations }\left(\frac{\text { regen }}{\text { year }}\right)
\end{aligned}
$$

\footnotetext{
${ }^{7}$ As previously noted, your system may not have a softener system. If this is the case, you will need to use the second methodology to estimate your steam system water use.
} 
If however, you can't reasonably estimate the amount of water passing through your softener system, the next methodology can be used as an alternative.

\subsection{Option 2: Determining Heating System Water Use Knowing Your Steam Generation Rate}

Most steam generation facilities track steam generation on per hour or per day basis. Knowing this variable, along with annual hours or days of operation and boiler cycles of concentration, the overall system annual water use can be determined ${ }^{8}$.

The following steps provide a methodology to determine the total amount of make-up water added to the boiler system over the course of 1 year.

To use this methodology, you need the following system parameters:

1. Steam generation rates from your boiler system(s)

2. Boiler cycles of concentration ${ }^{9}$

3. Condensate return rate

4. Annual days of operation

Your steam generation rate is typically logged and is likely tracked in terms of pounds per unit of time (hours or days). This value will need to be converted to gallons/time (hours or days) by dividing your steam generation rate by 8.314 pounds per gallon (lbs/gal) (the density of water) to ensure similar units are used for all calculations:

Formula 4: Steam Generation Rate $\left(\frac{\text { gal }}{\text { time }}\right)=$ Steam Rate $\left(\frac{l b s}{\text { time }}\right) \div 8.314\left(\frac{l b s}{g a l}\right)$

Knowing the steam generation rate in gallons, you have one component needed to solve boiler feed water rates according to this equation:

Formula 5: Feed Water Rate $\left(\frac{\text { gal }}{\text { time }}\right)=$ Steam Generation Rate $\left(\frac{\text { gal }}{\text { time }}\right)+$ Blowdown $\left(\frac{\text { gal }}{\text { time }}\right)$

The next step is to determine the blowdown rate of the system. Often, this flow is not measured because of differing methods of blowdown control (automated control systems versus manual methods), and the temperatures of the boiler bulk water. If this is the case, you can use another system measurement, cycles of concentration, to determine the percentage of boiler feed water blown down (also referred to as percent blowdown). Go to section 9.2 in the appendix to learn more about cycles of concentration, and how this value can be determined.

\footnotetext{
${ }^{8}$ This methodology provides means to calculate your steam system water use, rather than a rough estimation process.

${ }^{9}$ The term "cycles of concentration" is discussed in greater detail in section 9.2 of the appendix.
} 
If you don't measure your blowdown rate, you can use the following alternate calculation, incorporating cycles of concentration, to determine the feed water ${ }^{10}$ :

Formula 6: Feed Water Rate $\left(\frac{\text { gal }}{\text { time }}\right)=$

Steam Generation Rate $\left(\frac{\text { gal }}{\text { time }}\right) \div[1-(1 \div$ Cycles of Concentration $)]$

Now that you have the feed water rate, you need to determine the amount of condensate return coming back from your heating or process steam system. This will be a fraction of the steam generation rate, which is likely already tracked. Typical condensate return rates for institutional facilities are around $80 \%{ }^{11}$. These are facilities that predominantly utilize steam for comfort heating, but may have some process heating requirements, as well. If you know the amount of condensate return you have coming back to the boiler feed water, use it to accurately estimate your system. If you don't, use $80 \%$ of the steam generation rate as a safe rule of thumb. Use the following equation to calculate your makeup rate (make sure your unit of time is the same for all parameters):

Formula 7: Make - up $\left(\frac{\text { gal }}{\text { time }}\right)=$

Feed Water Rate $\left(\frac{\text { gal }}{\text { time }}\right)-\left[\right.$ Steam Generation Rate $\left(\frac{\text { gal }}{\text { time }}\right) \times \%$ steam returned $]$

Now that you have your make-up levels, use it and the average number of days your steam generating boiler(s) operate on a yearly basis to determine your annual usage, per the following equation. (This equation shows the time units in days. Make sure that your units stay consistent through these steps.)

Formula 8: Annual Usage $\left(\frac{g a l}{y e a r}\right)=$ Make - up $\left(\frac{g a l}{d a y}\right) \times$ Annual Days of Operation

To help explain this methodology better, an example scenario is provided in section 9.5 of the appendix.

\footnotetext{
${ }^{10}$ Refer to section 9.6 in the appendix for the steps leading to this equation.

${ }^{11}$ Condensate return range based on author's professional field experience and industry accepted standard levels.
} 


\subsection{Washing Applications Water Use}

Many Federal sites have washing applications that may fall into the industrial water use category. Some examples of washing applications are vehicle wash stations, glassware washing, and laboratory equipment washing. This section provides a methodology on how to estimate annual water use for these applications. First, this section provides guidance for generic wash applications, or batch process/manufacturing operations. It also provides guidance for water use in vehicle wash stations showing a distinct example estimating annual water use for an actual process.

\subsection{Wash Applications and Batch Processing/Manufacturing Usages}

You may have generic wash applications or batch processing/manufacturing applications at your installation. To determine these water using processes, you need the following:

1. The approximate number of units annually washed, processed, or manufactured

2. Estimated amount of water needed to wash, process, or manufacture each unit in gallons

3. Whether any recycle/reclaim operation is used expressed as a percentage

Use the following calculations to determine these uses:

Formula 9: Annual Usage $\left(\frac{\text { gal }}{\text { year }}\right)=(N \times W) \times(1-R)$

$N=$ Number of annual units washed, processed, or manufactured

$W=$ Gallons consumed per unit

$R=$ Percentage recycled or reused, expressed as a decimal (i.e. $40 \%$ will be expressed as 0.4 in the equation)

As an example, consider a manufacturing process that requires post-rinsing of each unit manufactured. If 20,000 units are manufactured each year, and it takes 2.3 gallons to wash each unit, and you know your system reuses $60 \%$ of this wash water, then the calculation is as follows:

$$
\begin{gathered}
\text { Annual Usage }\left(\frac{\text { gal }}{\text { year }}\right)=(20,000 \times 2.3) \times(1-0.6) \\
=\mathbf{1 8 , 4 0 0}\left(\frac{\text { gal }}{\text { year }}\right)
\end{gathered}
$$




\subsection{Vehicle Wash Stations}

If you know the amount of water it takes to wash one vehicle in your wash station, use the methodology described above to estimate your annual vehicle wash water use. If you don't have the gallons per vehicle amount, the information below offers an alternative approach.

Using this methodology to estimate water use in your vehicle wash station application(s), you need to have the following items:

1. Annual number of vehicles passing through wash facilities

2. Type of vehicle wash stations (self-service, in-bay automatics, or conveyor automatics)

3. If reclaim operations are employed at your vehicle wash station(s)

Depending on the type of vehicle wash station(s) you are using and your use of reclaim operations, you can calculate your annual usage using one of the following tables. There are two tables provided - one for systems without reclaim systems (Table 2 ) and one for systems with reclaim systems (Table 3 ). In each case, the table will provide you a range (low, average, and high) for the water use by your system(s). The background information for these tables is supplied in section 9.7 of the appendix. In short, the study (Brown 2002) surveyed various car wash facilities in three different climate zones to get a range of water use. The study takes into account statistical analysis to determine average levels for the different systems and low and high levels of water use based on standard deviation.

First, locate the appropriate table. Then locate the type of vehicle wash station you have in the lefthand column. This resource will give you a range of your water use based (low, average, and high levels) on the system(s) used. Multiply the value in the table by the total number of vehicles you wash annually to estimate the total water used. You can report your overall value as a range between the low, average, and high levels, or you can pick the level you think is most appropriate for your system. For example, if you wash mainly large vehicles in your wash station (such as trucks or utility vehicles), you should likely choose the high number from the table. 
Table 2: Estimating Annual Usage Without Reclaim Systems, where $\mathbf{N}=$ Number of Vehicles Washed Annually

\begin{tabular}{|l|c|c|c|}
\hline \multirow{2}{*}{ Car Wash Type } & \multicolumn{3}{|c|}{ Gallons per Vehicle } \\
\hline Self-service & Low & Average & High \\
\hline In-bay automatic & $12.0 \times \mathrm{N}$ & $15.0 \times \mathrm{N}$ & $18.0 \times \mathrm{N}$ \\
\hline Conveyor & $16.9 \times \mathrm{N}$ & $42.9 \times \mathrm{N}$ & $68.9 \times \mathrm{N}$ \\
\hline
\end{tabular}

Table 3: Estimating Annual Usage With Reclaim Systems, where $\mathbf{N}=$ Number of Vehicles Washed Annually

\begin{tabular}{|l|c|c|c|}
\hline & \multicolumn{3}{|c|}{ Gallons per Vehicle } \\
\hline Car Wash Type & Low & Average & High \\
\hline Self-service & $3.5 \times \mathrm{N}$ & $7.5 \times \mathrm{N}$ & $12.7 \times \mathrm{N}$ \\
\hline In-bay automatic & $4.9 \times \mathrm{N}$ & $21.3 \times \mathrm{N}$ & $48.5 \times \mathrm{N}$ \\
\hline Conveyor & $5.5 \times \mathrm{N}$ & $16.9 \times \mathrm{N}$ & $34.5 \times \mathrm{N}$ \\
\hline
\end{tabular}




\subsection{Subsequent Reporting Years}

Now that you've estimated your baseline for unmetered industrial water use, how will you document changes in water use for subsequent reporting years? The best approach is to install meters on these applications. This will offer you a way to check your baseline estimate and also accurately report any consumption changes in future years. If metering is not practical, you can use this document to report changes in water use by utilizing these same methodologies. This will not be entirely accurate, but it can provide you a methodology to estimate changes in industrial water usage for these applications. 


\subsection{Glossary}

Blowdown water: Water discharged from a boiler or cooling tower to remove high mineral content system water, impurities, and sediment.

Boiler feed water: The flow of supply water directly to the boiler. It is the combination of make-up water and condensate return, and accounts for steam generation and boiler blowdown.

Condensate return: Steam that changes back to the liquid phase after process or heating applications, that is subsequently pumped back to the boiler feed water.

Cooling tower drift: Escape of water droplets from the cooling tower structure as a result of system air flow and wind-effect air flow.

Deaerator: A component in the steam boiler system that uses pressure and elevated temperatures to reduce dissolved gas levels in the boiler feed water.

Demineralizer: Resin-based filtration equipment used to produce ultra pure water containing very few impurities.

Make-up water: Water supply needed to replace all losses due to evaporation, leaks, or discharge in boiler or cooling systems.

Reverse osmosis: Filtration method using high pressure to force water through tightly wound membranes producing ultra pure water containing very little impurities.

Sediment filters: Equipment that removes insoluble particulate matter from a solution.

Softener regeneration: The process softener systems go through to remove calcium, magnesium, dirt and silt that were previous filtered from the make-up water. After the softener is regenerated it can be placed back into service to provide softened water again to the system.

Steam rate: Steam generation from the boiler needed to meet the heating and/or process steam demand, usually expressed in pounds per time.

Water softener: Conditions water by removing hardness (calcium and magnesium). The process involves a simple exchange of sodium for less desirable calcium and magnesium components present in make-up water. 


\subsection{References}

Brown, Chris. 2002. Water Use in the Professional Cash Wash Industry. International Carwash Association. Chicago, Illinois.

Buecker, Brad. 1997. Power Plant Water Chemistry: A Practical Guide. PennWell Publishing Company, Tulsa, Oklahoma.

USGS. 2000. Estimated Use of Water in the United States in 2000. Accessed April 2010 at http://pubs.usgs.gov/circ/2004/circ1268/htdocs/text-in.html (undated webpage) 
Appendix 



\section{Appendix}

The following sections describe key concepts that are covered in this document to provide a technical explanation for the methodology used to help estimate industrial water usage. It is not necessary to read Appendix A to use the processes outlined in the main body of this document. Appendix A provides the reader detailed explanation of technical terms, and background information for the tables and calculations applied in the document.

\section{A-1 Total Dissolved Solids and Conductivity}

Total dissolved solids is expressed in term of parts per million (ppm), which is equivalent to milligrams per liter. The term total dissolved solids, refers to the precise amount of dissolved minerals present in a volume of water. It can be determined by weighing a given volume of water, then boiling all of the water away, and weighing the solids that remain. The ratio in terms of milligrams of solids per liter of water provides total dissolved solids in parts per million.

This value has largely been replaced as a field measurement by conductivity. Conductivity is a relative measurement of the mineral content dissolved in water in that it measures the water's ability to conduct electricity. It is not a proportional replacement of total dissolved solids, but provides an easy field measurement. Relatively pure water (minimal dissolved mineral content) will not conduct electricity as well as water with high levels of dissolved minerals.

In the absence of TDS measurement, conductivity can be used as a replacement to determine cycles of concentration using Formula 11 below.

\section{A-2 Cycles of Concentration}

Cycles of concentration, also referred to as concentration ratio, is a technical term used to describe the mass flow relationship between the amount of system feed water and the amount of blowdown sent down the drain. Cycles of concentration correlates to the effective use of water in your system to provide heating or cooling needs. High cycles of concentration are directly related to low levels of water loss from your system.

The following equation shows the simple relationship ${ }^{12}$ :

Formula 10: Cycles of Concentration $=\frac{\text { Feed Water Flow }}{\text { Blowdown Flow }}$

\footnotetext{
${ }^{12}$ Formula 10 illustrates the mass flow relationship of cycles of concentration. This document is only applicable if feed water flow is unknown, however the calculation provides a relationship to flow rates and cycles of concentration across a cooling tower. Determination of cycles can be accomplished by either Formula 10 or 11 .
} 
Accurate determination of cycles of concentration can be accomplished by direct measurement of make-up and blowdown flow rates, or by measuring the total dissolved solids (in parts per million, $\mathrm{mg} / \mathrm{liter}$ ) in the system bulk water and in the feed water. The ratio of these measurements by the following calculation also gives you cycles of concentration:

Formula 11: Cycles of Concentration $=\frac{\text { Total Dissolved Solids }(p p m) \text { Blowdown Water }}{\text { Total Dissolved Solids }(p p m) \text { Make }- \text { up Water }}$

As mentioned above, conductivity is a much more predominant field measurement than TDS and can be used in Formula 11 to make a rough determination of cycles of concentration. TDS or individual mineral components, such as chloride, sulfate, or magnesium are preferred for accuracy because conductivity can be impacted by temperature and certain treatment chemicals. Most sites with large heating and cooling loads that use open-recirculating cooling towers and steam generating boilers typically have the ability to measure conductivity and record this value on a routine basis. If cycles of concentration can be determined and blowdown flow can be measured or estimated, Formula 10 can be used to determine an estimated feed water flow rate.

Figure 3 below, illustrates cycles of concentration in terms of flow and TDS:

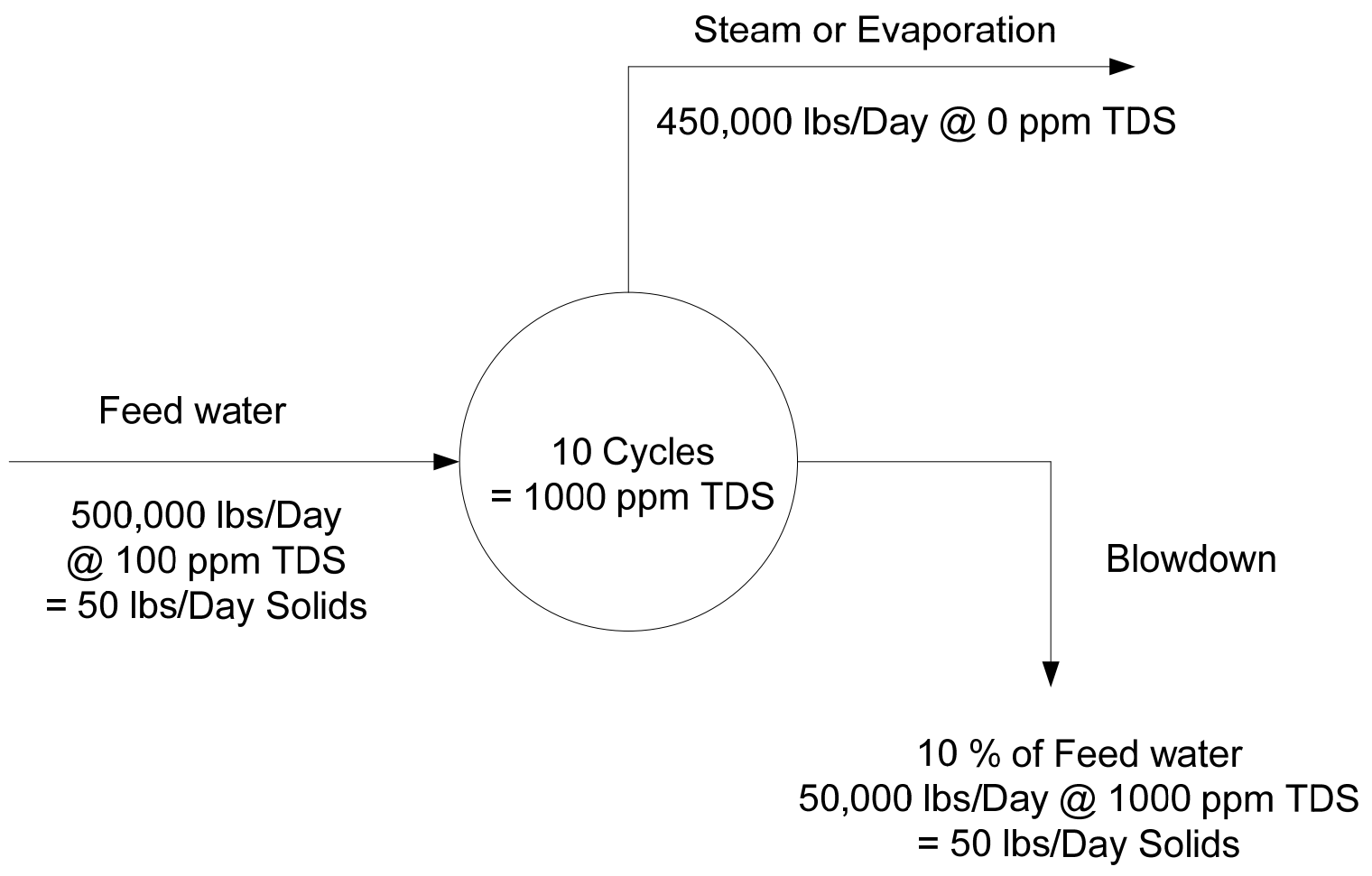

Figure A 1: Cycles of Concentration and Mass Flow Example of a Steam System

Solving each of the equations above for this example gives the following: 


$$
\begin{aligned}
& \text { Cycles of Concentration }=\frac{\text { Feed Water Flow }}{\text { Blowdown Flow }} \\
& =500,000(\text { lbs } / \text { day }) \div 50,000(\text { lbs } / \text { day }) \\
& =10 \\
& \text { Cycles of Concentration }=\frac{\text { Total Dissolved Solids }(p p m) \text { Blowdown Water }}{\text { Total Dissolved Solids }(p p m) \text { Make }- \text { up Water }} \\
& =1000 \mathrm{ppm} \div 100 \mathrm{ppm} \\
& =10
\end{aligned}
$$

\section{A-3 Cooling System Considerations}

The following equation shows the relationship of make-up and typical open-recirculating tower system losses:

Formula 12: Make - up $=$ Evaporation Rate + Blowdown + Drift

Below are the calculations used to solve Formula 2, and used to determine the values displayed in Table 1 (Buecker 1997, pg 161 - 163; GE 2010; Nalco 1988, pg 38.11-38.14):

Formula 13: Evaporation Rate $=$ Recirculation Rate $(\mathrm{gpm}) \times \Delta T \times 0.00085^{13}$

Formula 14: Recirculation Rate (rule of thumb) $=$ Tonnage $\times 3$

Formula 15: System Losses $=$ Make - up $=$ Evaporation Rate + Blowdown $=(($ Evap. Rate $\times$ Cycles of Concentration $)) /($ Cycles of Concentration -1$)$

Formula 11: Cycles of Concentration = TDS ppm Blowdown Water $\div$ TDS ppm Make - up Water

\section{Sample Calculation:}

Below is a sample scenario to demonstrate the application of these formulas to determine the values displayed in Table 1.

Example scenario:

Given - Chiller is rated for 100 tons of refrigeration

System $\Delta \mathrm{T}$ is 10 degree $\mathrm{F}$

5 cycles of concentration

Year-round operation

Recirculation Rate $($ rule of thumb) $=$ Tonnage $\times 3$

Recirculation Rate (rule of thumb) $=100 \times 3$

Recirculation Rate (rule of thumb) $=300 \mathrm{gpm}$

\footnotetext{
${ }^{13}$ This formula is valid when system $\Delta \mathrm{T}$ is measured in degrees Fahrenheit, and represents the condenser approach temperature. The condenser approach temperature is the difference between the condenser refrigerant temperature, and the exiting condenser water temperature.
} 
Evaporation Rate $=$ Recirculation Rate $(\mathrm{gpm}) \times \Delta T \times 0.00085$

Evaporation Rate $=300(\mathrm{gpm}) \times 10 \times 0.00085$

Evaporation Rate $=2.55(\mathrm{gpm}) \times 60\left(\frac{\mathrm{min}}{\mathrm{hr}}\right) \times 24\left(\frac{\mathrm{hr}}{\text { day }}\right) \times 365\left(\frac{\text { day }}{\text { year }}\right)$

Evaporation Rate $=1,340,280\left(\frac{\text { gal }}{\text { year }}\right)$

System Losses $=(($ Evap. Rate $\times$ Cycles of Concentration $)) /($ Cycles of Concentration -1$)$

System Losses $=\left(\left(1,340,280\left(\frac{\text { gal }}{\text { year }}\right) \times 5\right)\right) /(5-1)$

System Losses $=\mathbf{1 , 6 7 5 , 3 5 0}\left(\frac{\text { gal }}{\text { year }}\right)$

\section{A-4 Mass Balance of Steam Systems}

Understanding the mass balance relationship of a steam systems will help you to estimate water used in your system. Mass balance refers to equating the amount of water coming into the system with the amount of water going out. Two mass balance calculations can be applied to work back to the make-up amount, or overall system usage number.

The first mass balance calculation is centered on the boiler itself. The amount of boiler feed water into the boiler will equal the steam generation plus the blow down, as expressed by the following equation:

Formula 5: Feed Water Rate $\left(\frac{\text { gal }}{\text { time }}\right)=$ Steam Generation Rate $\left(\frac{\text { gal }}{\text { time }}\right)+$ Blowdown $\left(\frac{\text { gal }}{\text { time }}\right)$

After determining the feed water, the second mass balance equation incorporates the amount of condensed steam returned from the process or heating application. The amount of boiler feed water will also be equal to the condensate return plus the make-up water, as expressed by the following equation:

Formula 16: Feed Water Rate $\left(\frac{\text { gal }}{\text { time }}\right)=$ Condensate Return Rate $\left(\frac{\text { gal }}{\text { time }}\right)+$ Make - up Rate $\left(\frac{\text { gal }}{\text { time }}\right)$

As discussed above, the make-up requirement is equal to your total annual system losses or usages. Solving, then, for make-up, the equation becomes:

Formula 17: Make - up Rate $\left(\frac{\text { gal }}{\text { time }}\right)=$ Feed Water Rate $\left(\frac{\text { gal }}{\text { time }}\right)$ - Condensate Return Rate $\left(\frac{\text { gal }}{\text { time }}\right)$

\section{A-5 Explanation of Formula 6}

Formula 6: Feed Water Rate $\left(\frac{\text { gal }}{\text { time }}\right)$

$$
=\text { Steam Generation Rate }\left(\frac{\text { gal }}{\text { time }}\right) \div[1-(1 \div \text { Cycles of Concentration })]
$$

The following sequence of calculations provides the background for how this equation is determined: 
In mass flow terms:

Feed Water Rate $\left(\frac{\text { gal }}{\text { time }}\right)=$ Steam Generation Rate $\left(\frac{\text { gal }}{\text { time }}\right)+$ Blowdown $\left(\frac{\text { gal }}{\text { time }}\right)$

And:

Cycles of Concentration $=\frac{\text { Feed Water Flow }}{\text { Blowdown Flow }}$

Inserting in the mass flow calculation:

Feed Water $=$ Steam Generation Rate + Feed Water $\div$ Cycles of Concentration

Feed Water $\times$ Feed Water $\div$ Cycles of Concentration $=$ Steam Generation Rate

Feed Water $\times[1-(1 \div$ Cycles of Concentration $)]=$ Steam Generation Rate

Formula 6: Feed Water Rate $\left(\frac{\text { gal }}{\text { time }}\right)$

$$
=\text { Steam Generation Rate }\left(\frac{\text { gal }}{\text { time }}\right) \div[1-(1 \div \text { Cycles of Concentration })]
$$

\section{A-6 Steam Heating System Example}

Below is a sample scenario to demonstrate the methodology used to calculate system usage knowing your steam generation rate, your boiler cycles of concentration, and your annual days of operation.

Example scenario:

Given - Steam rate is $750,000 \mathrm{lbs} /$ day

Boiler feed water TDS is measured to be 100 ppm (mg/liter)

Boiler bulk water TDS is measured to be 1500 ppm (mg/liter)

Estimated condensate return is $80 \%$ of steam generation, or $600,000 \mathrm{lbs} / \mathrm{day}$

Boiler operates 350 days in a typical year

Figure $A-2$, on the following page depicts this scenario graphically. 


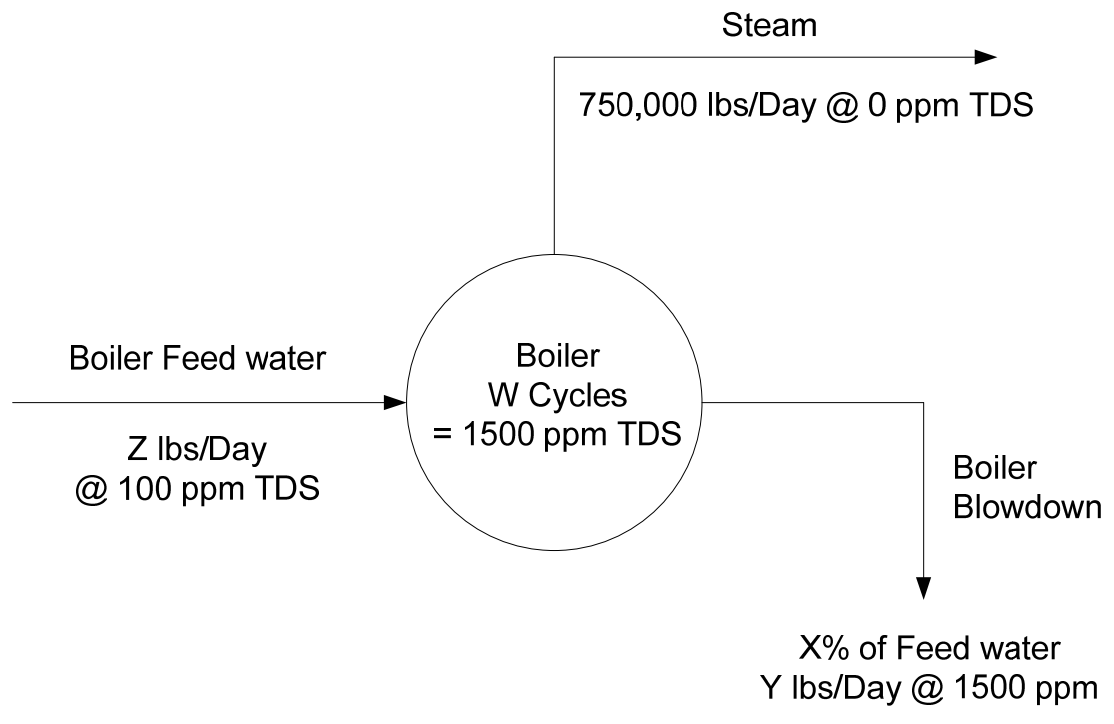

Figure A 2: Sample Boiler Scenario

Remembering the mass balance of the steam system (as described above), the first determination will be cycles of concentration (W) using the boiler water TDS and the feed water TDS:

Cycles of Concentration $=\frac{\text { Total Dissolved Solids }(p p m) \text { System Bulk Water }}{\text { Total Dissolved Solids }(p p m) \text { Make up Water }}$

$$
\begin{gathered}
=1500 \mathrm{ppm} \div 100 \mathrm{ppm} \\
=15
\end{gathered}
$$

This variable is also equal to the ration between the flow of feed water and the flow of blowdown:

Cycles of Concentration $=\frac{\text { Feed Water Flow }}{\text { Blowdown Flow }}$

Or

$15=Z \div Y$, or $Z=15 \times Y$, or $Y=Z \div 15$

A second formula is needed to solve for $\mathrm{Z}$ and $\mathrm{Y}$. The mass balance will be:

Feed Water Rate $\left(\frac{\text { gal }}{\text { time }}\right)=$ Steam Generation Rate $\left(\frac{\text { gal }}{\text { time }}\right)+$ Blowdown $\left(\frac{\text { gal }}{\text { time }}\right)$

Or

$Z\left(\frac{l b s}{d a y}\right)=750,000\left(\frac{l b s}{d a y}\right)+Y\left(\frac{l b s}{d a y}\right)$

Combining the two equations, and solving for $\mathrm{Z}$ (feed water rate):

$Z=750,000 \frac{l b s}{d a y}+(Z \div 15)$ 


$$
\begin{aligned}
& Z-(Z \div 15)=750,000\left(\frac{l b s}{\text { day }}\right) \\
& Z[1-(1 \div 15)]=750,000\left(\frac{l b s}{\text { day }}\right) \\
& Z=750,000\left(\frac{l b s}{\text { day }}\right) \div\left[(1-(1 \div 15)]=750,000\left(\frac{l b s}{\text { day }}\right) \div[1-0.067]=750,000\left(\frac{l b s}{d a y}\right) \div 0.933\right. \\
& \quad=803,859\left(\frac{l b s}{d a y}\right)
\end{aligned}
$$

The boiler feed water is also equal to the amount of make-up water and condensate return, as expressed by the following formula:

Boiler Feed Water $=$ Condensate Return + Make - up

Solving for make-up flow, the formula ends up being:

$$
\begin{aligned}
\text { Make }- \text { up }= & \text { Boiler Feed Water }- \text { Condensate Return } \\
\text { Make }- \text { up }= & 803,859\left(\frac{l b s}{\text { day }}\right)-600,000\left(\frac{l b s}{\text { day }}\right) \\
& =203,859\left(\frac{l b s}{\text { day }}\right) \div 8.314\left(\frac{l b s}{\text { gal }}\right) \\
& =24,520\left(\frac{\text { gal }}{\text { day }}\right)
\end{aligned}
$$

Annual usage for this scenario then becomes:

$$
\begin{array}{r}
\text { Annual Usage }=24,520\left(\frac{\text { gal }}{\text { day }}\right) \times 350\left(\frac{\text { days }}{\text { year }}\right) \\
=\mathbf{8 . 5 8}\left(\frac{\text { million gal }}{\text { year }}\right)
\end{array}
$$

\section{A-7 Vehicle Wash Considerations}

Depending on the type of vehicle wash station employed at your installation, the following table (Table 4) provides a range of fresh water usage in gallons per vehicle (Brown 2002):

Table 4: Average Fresh Water Usage by Car Wash Type

\begin{tabular}{|l|c|c|c|}
\hline & \multicolumn{2}{|c|}{ Gallons per Vehicle } \\
\hline Car Wash Type & Low & Average & High \\
\hline Self-service & 12.0 & 15.0 & 68.9 \\
\hline In-bay automatic & 16.9 & 42.9 & 49.0 \\
\hline Conveyor & 19.0 & 34.0 & \\
\hline
\end{tabular}


It should be noted that the study referenced covers different types of car washes, and your facility may typically be washing larger vehicles. If this is the case, use the high figures to estimate your annual usage rather than the mean or low.

Knowing the annual number of vehicles passing through the wash facilities and the type of facility you have, usage ranges (high, low, and average) can be estimated.

If your installation employs reclaim systems, the amount of water recycled should be accounted for to reduce your reported usage levels. Unfortunately, reclaim systems and their cumulative recycle levels can vary depending on system type and the extent of the reclaim operation.

The report cited also surveyed 11 different sites using reclaim systems and recorded high and low reclaim percentages. Taking the results logged from these sites, and calculating average and standard deviation figures gives the following range (Table 5) to estimate the percentage of system water reclaimed:

Table 5: Percent Reclaim Levels

\begin{tabular}{|c|c|c|}
\hline Low & Average & High \\
\hline $29.62 \%$ & $50.27 \%$ & $70.92 \%$ \\
\hline
\end{tabular}

\section{A-8 Appendix References}

Brown, Chris. 2002. Water Use in the Professional Cash Wash Industry. International Carwash Association. Chicago, Illinois.

Buecker, Brad. 1997. Power Plant Water Chemistry: A Practical Guide. PennWell Publishing Company, Tulsa, Oklahoma.

GE - General Electric Company. 2010. GE Water Handbook. Accessed April 2010 at http://www.gewater.com/handbook/cooling water systems/ch 31 open.jsp (undated webpage).

Nalco - Nalco Company. 1988. The Nalco Water Handbook. Second Edition. McGraw-Hill Book Company, New York, New York 


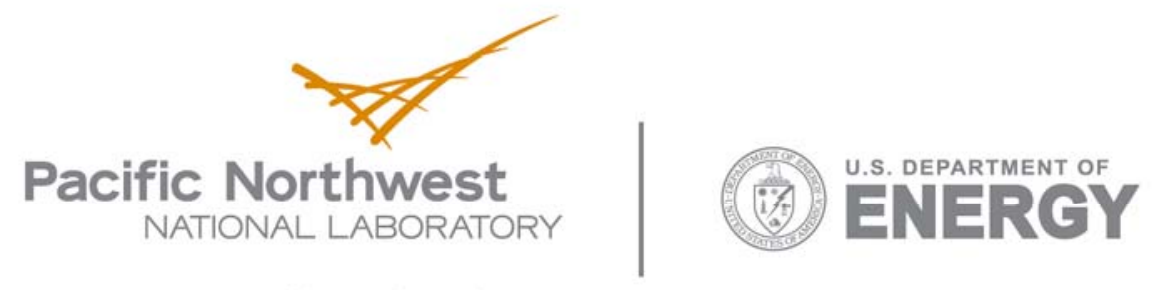

902 Battelle Boulevard

P.O. Box 999

Richland, WA 99352

1-888-375-PNNL (7665)

www.pnl.gov 